\title{
Resíduos sólidos urbanos no Estado da Paraíba e o contexto da sustentabilidade ambiental
}

\author{
Urban solid waste in the State of Paraíba and the context of environmental sustainability \\ Residuos sólidos urbanos en el Estado de Paraíba y el contexto de sostenibilidad ambiental
}

Recebido: 08/01/2021 | Revisado: 10/01/2021 | Aceito: 13/01/2021 | Publicado: 17/01/2021

\author{
Valderi Duarte Leite \\ ORCID: https://orcid.org/0000-0001-5861-7407 \\ Universidade Estadual da Paraíba, Brasil \\ E-mail: mangabeiraleite@gmail.com \\ Wilton Silva Lopes \\ ORCID: https://orcid.org/0000-0002-0151-7664 \\ Universidade Estadual da Paraíba, Brasil \\ E-mail: wiltonuepb@gmail.com \\ José Tavares de Sousa \\ ORCID: https://orcid.org/0000-0002-1056-1771 \\ Universidade Estadual da Paraíba, Brasil \\ E-mail: tavaresuepb@gmail.com \\ Maria Virgínia da Conceição Albuquerque
ORCID: https://orcid.org/0000-0001-5060-584X \\ Universidade Estadual da Paraíba, Brasil \\ E-mail: virginiaalbuquerque.uepb@gmail.com \\ Maria Célia Cavalcante de Paula e Silva \\ ORCID: https://orcid.org/0000-0001-6391-0261 \\ Universidade Estadual da Paraíba, Brasil \\ E-mail: celia_romulo@hotmail.com \\ Amanda da Silva Barbosa Cartaxo \\ ORCID: https://orcid.org/0000-0002-2514-6941 \\ Universidade Estadual da Paraíba, Brasil \\ E-mail: amandauepbbio@gmail.com \\ Gabriely Dias Dantas \\ ORCID: https://orcid.org/0000-0002-8684-7581 \\ Universidade Estadual da Paraíba, Brasil \\ E-mail: gabrielydias4@gmail.com
}

\begin{abstract}
Resumo
Este estudo avaliou a taxa de produção per capita de resíduos sólidos urbanos, bem como identificou os principais mecanismos de disposição final e tratamentos dos resíduos sólidos urbanos coletados do estado da Paraíba. No Brasil a produção per capita de resíduos sólidos urbanos é estimada em $1 \mathrm{~kg}$. (hab.dia) ${ }^{-1}$, sendo produzido diariamente algo em torno de 210 mil toneladas e coletados diariamente em média 172 mil toneladas. Verificou-se que os serviços de limpeza pública, neste estado, do quantitativo dos resíduos sólidos urbanos produzidos, são coletados atualmente algo em torno de $93 \%$ e da fração coletada, $40 \%$ em média está sendo confinada em aterros sanitários que estão localizados na região metropolitana da cidade de João Pessoa e na cidade de Campina Grande. A quantidade estimada de resíduos sólidos urbanos coletados diariamente é de 2.600 toneladas.dia $^{-1}$, o que corresponde a um quantitativo de matéria orgânica putrescível de aproximadamente $1.430,000$ toneladas.dia ${ }^{-1}$. Portanto, considerando apenas esta matriz de produção de matéria orgânica putrescível e que esta matéria orgânica será utilizada para produção de composto orgânico, seria produzida um total de 858,0 toneladas de composto orgânico.dia ${ }^{-1}$, o que propiciaria uma aplicação de 15,9 toneladas de composto orgânico (hab.ano) ${ }^{-1}$, na área potencialmente agricultável. Pode-se afirmar também, que não é seguro em nenhum aspecto o confinamento de resíduos sólidos urbanos em aterro sanitário, haja vista a complexidade do processo de confinamento em si, a demanda de área requerida e custos financeiros associados, além dos subprodutos gerados e dos impactos ambientais do entorno.
\end{abstract}

Palavras-chave: Saneamento básico; Limpeza urbana; Sustentabilidade agrícola.

\section{Abstract}

This study evaluated the rate of per capita production of solid urban waste, as well as identified the main mechanisms for final disposal and treatment of solid urban waste collected from the state of Paraíba. In Brazil, the per capita production of solid urban waste is estimated at $1 \mathrm{~kg}$. (hab.dia) ${ }^{-1}$, being produced around 210 thousand tons daily and collected on average 172 thousand tons daily. It was found that public cleaning services, in this state, of the amount of 
solid urban waste produced, are currently collected around $93 \%$ and of the fraction collected, $40 \%$ on average is being confined in landfills that are located in the region metropolitan area of the city of João Pessoa and in the city of Campina Grande. The estimated amount of solid urban waste collected daily is 2.600 tons.day $^{-1}$, which corresponds to a quantity of putrescible organic matter of approximately 1.430 .000 tons day $^{-1}$. Therefore, considering only this matrix of production of putrescible organic matter and that this organic matter will be used for the production of organic compost, a total of 858.0 tons of organic compost would be produced. day ${ }^{-1}$, which would provide an application of 15.9 tons of organic compost (ha.year) ${ }^{-1}$, in the potentially arable area. It can also be said that the containment of urban solid waste in a landfill is not safe in any respect, given the complexity of the containment process itself, the required area demand and associated financial costs, in addition to the by-products generated and the environmental impacts of the surroundings.

Keywords: Basic sanitation; Urban cleanliness; Agricultural sustainability.

\section{Resumen}

Este estudio evaluó la tasa de producción per cápita de residuos sólidos urbanos, así como identificó los principales mecanismos de disposición final y tratamiento de los residuos sólidos urbanos recolectados en el estado de Paraíba. En Brasil, la producción per cápita de residuos sólidos urbanos se estima en $1 \mathrm{~kg}$. (hab.dia) ${ }^{-1}$, produciéndose alrededor de 210 mil toneladas diarias y recolectadas en promedio 172 mil toneladas diarias. Se encontró que los servicios públicos de limpieza, en este estado, de la cantidad de residuos sólidos urbanos producidos, actualmente se recolectan alrededor del $93 \%$ y de la fracción recolectada, el $40 \%$ en promedio se encuentra confinada en rellenos sanitarios que se ubican en la región área metropolitana de João Pessoa y Campina Grande. La cantidad estimada de residuos sólidos urbanos recolectados diariamente es de 2.600 toneladas.día-1, lo que corresponde a una cantidad de materia orgánica putrescible de aproximadamente 1.430 .000 toneladas.día ${ }^{-1}$. Por lo tanto, considerando solo esta matriz de producción de materia orgánica putrescible y que esta materia orgánica será utilizada para la producción de compost orgánico, se produciría un total de 858.0 toneladas de compost orgánico. día ${ }^{-1}$, que proporcionaría una aplicación de 15,9 toneladas de abono orgánico (ha. año) ${ }^{-1}$, en el área potencialmente cultivable. También se puede decir que la contención de residuos sólidos urbanos en un relleno sanitario no es segura en ningún aspecto, dada la complejidad del propio proceso de contención, la demanda del área requerida y los costos financieros asociados, además de los subproductos generados y la impactos ambientales del entorno.

Palabras clave: Saneamiento; Limpieza urbana; Sostenibilidad agrícola.

\section{Introdução}

Registra-se que por volta do ano 10.000 a.c, os seres humanos iniciaram a sua organização em grupo e consequentemente passou a existir de forma mais substanciada e pontualizada a geração de resíduos sólidos, em especial de resíduos sólidos advindos das atividades humanas (Leite et al., 2009).

Com a advento da Revolução Industrial, passou a existir a formação de aglomerados urbanos, haja vista a dinâmica social e econômica instalada no seio da própria revolução, propiciando de forma mais acentuada o aumento expressivo de pessoas residindo em aglomerados urbanos e consequentemente por razões das relações já estabelecidas entre capital e trabalho, brotavam as demandas das questões inerentes ao Saneamento Básico e que nunca foram pautadas nas proporções devidas. O lastro destas demandas foi sendo agudizado ao longo da história da humanidade e com recrudescimento exploratório do sistema capitalista ainda hoje nos países periféricos estas demandas continuam perdurando intensamente (Leite et al., 2010).

Segundo dados do PNAD (2014) o Brasil é o $5^{\circ}$ maior país do mundo e o maior da América do Sul em extensão territorial. Da população total do Brasil, estimada atualmente em 210 milhões de habitantes, 15\% reside em áreas rurais e $85 \%$ nos centros urbanos, o que já representa um grande gargalho, em especial no que concerne as questões de infraestrutura, em especial as associadas ao Saneamento Básico (Leite et al., 2019). As emissões de resíduos sólidos são originadas principalmente das atividades domiciliares, urbanas, industriais, de serviços de saúde, de atividades de saneamento básico, atividades agrícolas, de transporte e mineração. No ano de 2010 no Brasil, foram geradas algo em torno de 71,2 milhões de toneladas de resíduos sólidos, sendo os resíduos sólidos urbanos responsável por 52,5\% do total das emissões. A produção per capita de resíduos sólidos é estimada em $1 \mathrm{~kg}$. (hab.dia) ${ }^{-1}$, sendo, portanto, produzido diariamente em média de 210 mil toneladas e coletados regularmente por dia 172 mil toneladas (Abrelpe, 2017). A composição gravimétrica dos resíduos sólidos urbanos produzidos pela população brasileira é constituída basicamente de matéria orgânica putrescível, papel, papelão, plásticos de diferentes 
fontes de produção e utilização, vidro, material ferroso e não ferroso e de diferentes outros tipos de resíduos, os denominados rejeitos (Leite et al., 2010).

No geral, a fração mais representativa em termos quantitativos é a matéria orgânica putrescível, que é de 55\% (percentagem em peso) e é detentora de capacidade total de utilização, tal qual as demais frações com exceção dos resíduos denominados rejeitos, que são resíduos sem classificação definida. Portanto, em termos quantitativos, dos resíduos sólidos urbanos produzidos e coletados ou não em todo o território brasileiro, 90\% poderão voltar de forma sustentável para o ciclo produtivo, contribuindo significativamente para a redução da presença dos denominados Lixões e Aterros Controlados, propiciando a otimização da vida útil dos Aterros Sanitários e a redução dos impactos ambientais associados (Figueiredo, 2011).

Na Tabela 1 são apresentados os dados advindos da caracterização gravimétrica dos resíduos sólidos urbanos (RSU) produzidos pela população brasileira. Salienta-se que frente a uma série de fatores de ordem social, econômica e ambiental, estes dados poderão sofrer variações, sendo necessária estabelecimento de critérios técnicos no processo de análise destes dados e a sua consequente utilização para projeto de sistemas de coleta e tratamento ou destinação final.

Tabela 1. Dados das variações típicas da composição gravimétrica dos RSU produzidos pela população brasileira nos últimos 10 anos.

\begin{tabular}{c|c}
\hline Componentes & Variação Percentual (\%p/p) \\
\hline Matéria orgânica fermentável & 56,0 a 60,0 \\
Metal ferroso & 1,50 a 1,80 \\
Metal não ferroso & 1,50 a 1,90 \\
Plástico mole & 8,5 a 9,0 \\
Plásticos duro & 4,0 a 4,5 \\
Vidro & 1,0 a 1,2 \\
Papel/papelão & 12,0 a 14,0 \\
Borracha, madeira e couro & 5,0 a 6,0 \\
Rejeitos & 10,0 a 12,0 \\
\hline
\end{tabular}

Fonte: Leite (2012).

Analisando os dados da caracterização física dos RSU apresentados na Tabela 1, pode ser percebido que os resíduos sólidos urbanos gerados e coletados no Brasil, são detentores de um percentual de $85 \%$ (percentagem em peso) de materiais com potencial de retornarem ao ciclo produtivo, restando apenas 15\% a serem destinados em aterros sanitários.

Na Figura 1 apresenta-se as projeções das principais alternativas tecnológicas empregadas para a destinação final (lixão, aterro controlado e aterro sanitário) de resíduos sólidos urbanos gerados e coletados em todo território nacional. As projeções foram construídas levando-se em consideração as tendências do crescimento do produto interno bruto do Brasil no período compreendido do ano 2005 a 2050.

Levando-se em consideração as projeções apresentadas na Figura 1, pode ser constatado que somente no ano de 2050 é que será alcançada a erradicação total dos lixões e aterros controlados (A.C) como alternativa de disposição final de resíduos sólidos urbanos, caso não haja redução no crescimento do produto interno bruto. Analisando os cenários de crescimento e redução do PIB brasileiro no período de 2000 a 2016, pode ser constatada que a variação foi de retração de $-3,8 \%$ no ano de 2015 a um expressivo crescimento de 7,5\% no ano de 2010. 
Figura 1. Comportamento da variação temporal das principais alternativas de disposição final de resíduos sólidos urbanos.

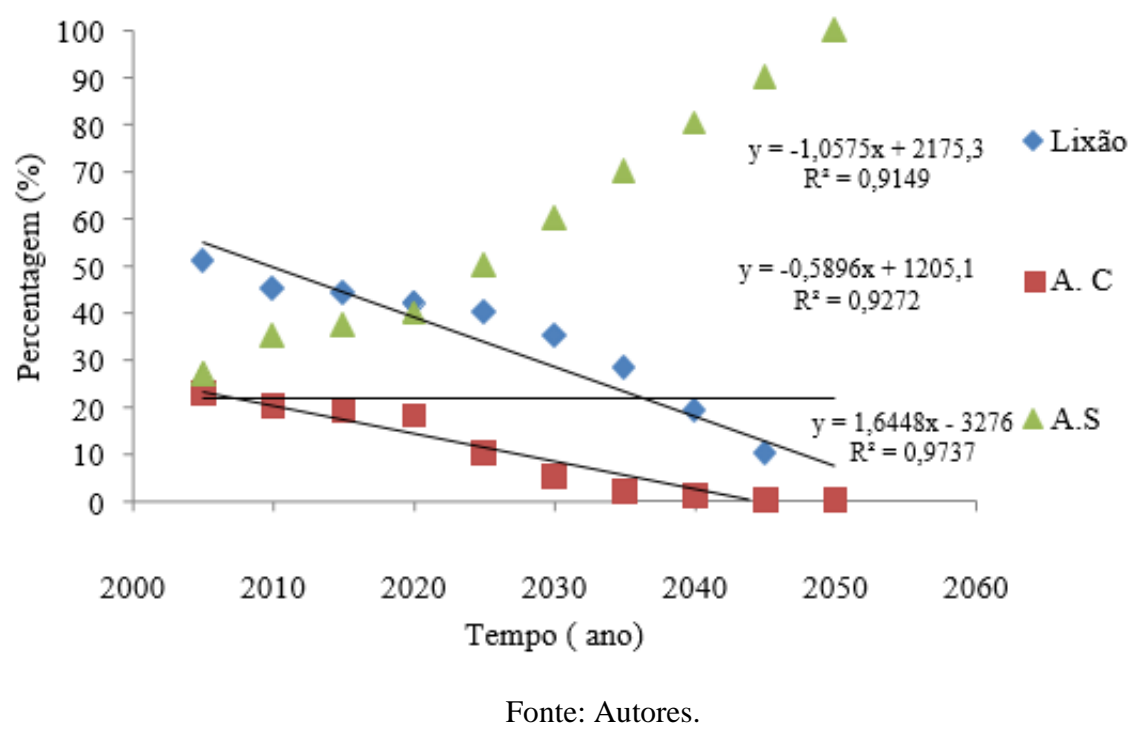

Como o crescimento do PIB é função do consumo privado, investimento privado, gastos públicos e da balança comercial, basta tão somente ajustar estes parâmetros para que o PIB volte a crescer de forma harmônica e sustentável. No ano de 2009, o PIB brasileiro retraiu em - $0,1 \%$, porém os investimentos em saneamento básico alcançaram o percentual de $0,2 \%$ e o impacto gerado foi bastante significativo. Portanto, mesmo reconhecendo as flutuações no produto interno bruto brasileiro, o investimento em saneamento básico poderia ser priorizado, adotando-se um percentual fixo do PIB acima de $0,2 \%$ e os problemas associados as demandas de saneamento básico seriam resolvidas em um período mais curto de tempo, bastando para isto tão somente determinação e vontade política do Governo Federal e dos Governos Estaduais.

No Brasil no ano de 2010 foi instituída a Política Nacional dos Resíduos Sólidos (PNRS), através da Lei ${ }^{\circ}$ 12.305/2010. Esta lei é considerada um dos marcos legais em todo a dinâmica processual dos resíduos sólidos e em especial dos resíduos sólidos urbanos (Brasil, 2010). As diretrizes da Política Nacional dos Resíduos Sólidos (PNRS), foi instituída pelo Decreto $\mathrm{n}^{\circ} 7.404 / 2010$ e que trata o conjunto dos diplomas jurídicos, objetivados para nortear estratégias que possam possibilitar otimização operacional, desde a geração até a destinação final e ou tratamento dos resíduos sólidos urbanos gerados e coletados (Brasil, 2012). Ressalta-se que os diplomas jurídicos ancorados na Política Nacional dos Resíduos Sólidos (PNRS), estão articulados diretamente com a Política Nacional de Educação Ambiental, que é regulada pela Lei n $9.795 / 1999$ e com a Política Federal de Saneamento Básico, regulamentado pelas Leis números 11.445/2007 e 11.107/2005 (Jacobi et al., 2011). Vale frisar ainda que com a legalização da PNRS, os gestores públicos, as empresas, a comunidade científica em todas as suas vertentes de atividades e a sociedade em geral são agentes corresponsáveis pelo enquadramento das premissas do Desenvolvimento Sustentável no que diz respeito à gestão dos RSU no Brasil (Leite et al., 2010).

No geral, os princípios norteadores da política nacional dos resíduos sólidos urbanos, são ancorados na não geração, na redução da geração e na inclusão à cadeia produtiva de forma ambientalmente sustentável das frações geradas dos resíduos sólidos urbanos (Lino et al., 2013).

O estado da Paraíba está situado geograficamente na região leste do nordeste do Brasil e limita-se com os estados do Rio grande do Norte ao Norte, Pernambuco ao Sul, Ceará ao Oeste e ao Oceano Atlântico ao Leste e possui área territorial de $56.372 \mathrm{~km}^{2}$. É detentor de uma população estimada em 4.025.558 habitantes e deste total algo em torno de 85,3\% reside atualmente no meio urbano (IBGE, 2013). É o $13^{0}$ lugar em população em nível nacional, contribuindo apenas com $2,3 \%$ da população brasileira. Da população urbana, 56,2\% está concentrada nas 10 maiores cidades, e 42,5 \% nas quatro maiores 
cidades que são João Pessoa, Campina Grande, Santa Rita e Patos. A área territorial do estado é constituída politicamente por 223 municípios, com densidade demográfica de 66,7 habitantes. $\mathrm{km}^{-2}$. Dos 223 municípios Paraibanos, apenas 04 municípios têm população superior a 100 mil habitantes, que são: João Pessoa, Campina Grande, Santa Rita e Patos. Salienta-se que o quantitativo populacional nas diversas cidades do estado da Paraíba varia de 1.792 a 720.789 habitantes, denotando uma variação altamente significativa, porém expressa um retrato da população das demais cidades dos estados brasileiros.

No tocante ao saneamento básico, $96,1 \%$ da população urbana do estado, têm acesso a água potável por rede de abastecimento e na zona rural o atendimento do abastecimento de água potável atende algo em torno de 35,4\% (PNAD, 2014). Em relação ao esgotamento sanitário, o princípio da universalização do acesso não é alcançado para 50,7\% dos domicílios, indicando desta forma, que pouco mais da metade da população esteja passível de riscos inerentes a ausência ou deficiência de saneamento básico.

Com relação aos serviços de limpeza pública, do quantitativo dos resíduos sólidos urbanos produzidos, são coletados regularmente $93 \%$ e da fração coletada, $40 \%$ em média está sendo confinada em aterros sanitários que estão localizados na região metropolitana da cidade de João Pessoa e na cidade de Campina Grande (Leite et al., 2010).

Na Figura 2 pode ser observada as tendências dos serviços de abastecimento de água (SAA), serviços de esgotamento sanitário (SES) e serviços de limpeza pública (SLP), no intervalo de tempo do ano de 2010 a 2033, para a população urbana do estado da Paraíba. Vale salientar que estas tendências foram construídas dentro de um cenário bem mais promissor do que o atual e isto significa dizer que estas tendências não sejam alcançadas dentro do prazo estipulado. No caso específico dos serviços de limpeza urbana, a tendência é de que no ano de 2033 a universalização seja alcançada e isto significa dizer que todos os resíduos sólidos urbanos produzidos pela população urbana do estado da Paraíba sejam coletados regularmente.

Figura 2. Tendências das metas dos principais indicadores de saneamento básico.

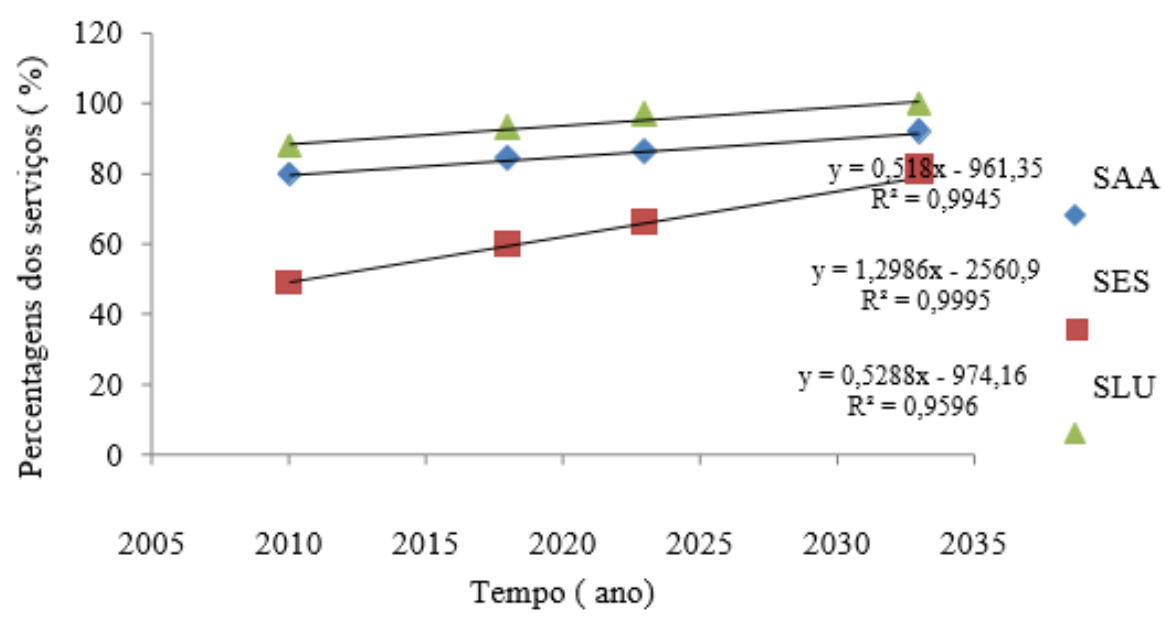

Fonte: Autores.

Com relação aos demais parâmetros, a situação é bem mais complexa, haja vista nos anos de 2033 ainda restaria $8 \%$ da população paraibana sem ser atendida por serviços de abastecimento público de água potável e $20 \%$ sem atendimento de serviços de esgotamento sanitário.

Neste sentido, este estudo avaliou a taxa de produção per capita de resíduos sólidos urbanos, além de identificar quais são os mecanismos de disposição final e tratamento dos resíduos sólidos urbanos coletados, no estado da Paraíba. 


\section{Metodologia}

A metodologia utilizada no estudo foi método quali-quantitativo. Segundo Pereira et al., 2018, nos métodos qualiquantitativos, faz-se a coleta de dados quantitativos ou numéricos por meio do uso de medições de grandezas e obtém-se por meio da metrologia, números com suas respectivas unidades. Estes métodos geram conjuntos ou massas de dados que podem ser analisados pelo pesquisador por meio de técnicas matemáticas como é o caso das porcentagens, estatísticas e probabilidades, métodos numéricos, métodos analíticos e geração de equações e/ou fórmulas matemáticas aplicáveis a algum processo.

Para tanto, o estudo foi realizado nas principais cidades do estado da Paraíba. Nas cidades de João pessoa e Campina Grande onde se concentra em média de $31 \%$ da população urbana do Estado, estão localizados os principais pólos educacionais, turísticos e industriais, os resíduos sólidos urbanos são coletados regularmente e confinados em aterros sanitários.

Na Figura 3 apresenta-se o mapa do estado da Paraíba, sendo destacada as suas principais mesorregiões que são: Sertão Paraibano, Borborema, Agreste e Mata Paraibana. A mesorregião do Sertão Paraibano é a $3^{\text {a }}$ mais populosa do Estado e é subdividida em sete microrregiões onde são geograficamente distribuídos 83 municípios, passando a ser a mesorregião com maior número de municípios A mesorregião da Borborema é a menos populosa do estado e estão instalados legalmente 44 municípios. A mesorregião da Mata Paraibana é a mais importante e é formada por 30 municípios e está localizada na região litorânea. A mesorregião do Agreste Paraibano é a $2^{\mathrm{a}}$ mais populosa e é constituída por 66 municípios.

Figura 3. Mapa geográfico do estado da Paraíba com destaque para as mesorregiões.

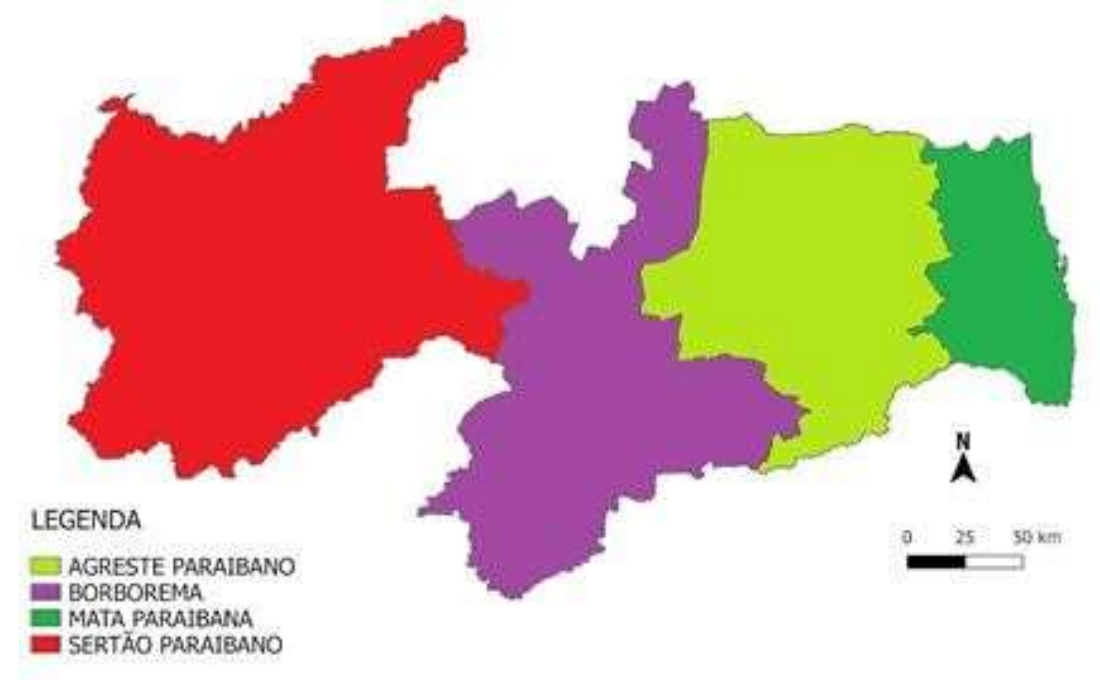

Fonte: Suporte geográfico

Elaborado a partir de base cartográfica do IBGE

Fonte: Autores.

Para a determinação do quantitativo de resíduos sólidos urbanos gerados no estado da Paraíba em um intervalo X de tempo, foi aplicada a Equação 1.

$$
\mathrm{QRSU}_{\mathrm{RU}}=\text { População total. TPP. }
$$

QRsU: quantidade de RSU gerada . (kg. dia ${ }^{-1}$ )

PTT: taxa de produção per capita $\left(\mathrm{kg} \cdot \mathrm{hab}^{-1}\right.$. dia $\left.{ }^{-1}\right)$. 
Para a determinação do quantitativo de resíduos sólidos urbanos coletados na Paraíba, foi aplicada a Equação 2.

$$
\mathrm{Q}_{\mathrm{RSU}}(\mathrm{C})=\text { População urbana } . \mathrm{TPP} \text {. \%SLP }
$$

SLP: serviço de limpeza pública

Para situações em que não são conhecidas com fidedignidade as taxas de produções per capitas de resíduos sólidos urbanos produzidos diariamente, estas poderão ser determinadas aplicando- se a Equação 3.

$$
\mathrm{TPP}=\mathrm{QRSU}_{\mathrm{RU}} /(\text { população. tempo })
$$

TPP: taxa de produção per capita $\left(\mathrm{kg} . \mathrm{hab}^{-1} \cdot \mathrm{dia}^{-1}\right)$. t: tempo de geração dos RSU (dia).

$\mathrm{Q}_{\mathrm{RSU}}$ : quantidade de resíduos sólidos urbanos gerados (kg).

Recomenda-se que esta operação seja realizada repetidas vezes e em diferentes estações do ano, haja vista a complexidade inerente a composição gravimétrica dos resíduos sólidos urbanos, além de fatores externos que influenciam diretamente os aspectos qualitativos e quantitativos deste parâmetro.

\section{Resultados e Discussão}

No Brasil, do quantitativo de RSU gerados diariamente que no ano de 2015 foi de 218.847 toneladas, a emissão de material orgânico putrescível foi de 122.554 toneladas.dia-1 ${ }^{-1}$ que deveria ser aproveitada integralmente para produção de energia ou de composto orgânico. Atualmente, este quantitativo diário produzido de material orgânico putrescível está sendo confinado em aterro sanitário o que equivale a 71.081 toneladas.dia ${ }^{-1}$, que frente ao processo de biodegradação anaeróbia passará a gerar biogás, constituído basicamente de $\mathrm{CO}_{2}$ e $\mathrm{CH}_{4}(\mathrm{GEE})$ e lixiviado com potencial poluidor de aproximadamente 25 superior ao de esgoto doméstico, quando considerado apenas material carbonáceo e nitrogenado. Ademais, resta ainda 50.247 toneladas.dia $^{-1}$ que são destinadas aos denominados aterros controlados e lixões, que quando não são utilizados por outras fontes, são biodegradados e passam a gerar biogás e lixiviado, só que de forma não controlada, propiciando impactos ambientais de diferentes magnitudes ao solo, a água e ao ar.

Pode ser levada em consideração ainda, que existem outras fontes potenciais de emissões de resíduos sólidos de natureza orgânica putrescível, que são as indústrias de processamentos de derivados de frutas, verduras, laticínios, carnes e as sucroalcooleiras e que algumas destas indústrias já aproveitam grande parte dos resíduos gerados na matriz energética endógena.

Analisando o contexto geral das emissões de resíduos sólidos no âmbito do território brasileiro, é urgente e necessário a implementação de políticas públicas que possam contribuir a curto e médio prazo para a redução de geração de resíduos sólidos e do tratamento racional do quantitativo gerado, levando em consideração o atendimento das demandas locais e regionais da aplicação dos subprodutos gerados.

No caso específico do estado da Paraíba, algo em torno de 45\% dos RSU coletados são confinados em aterros sanitários, que são os casos específicos do aterro sanitário da região metropolitana da cidade de João Pessoa e o aterro sanitário da região metropolitana da cidade de Campina Grande. Para os resíduos sólidos urbanos gerados e coletados pela população nas demais cidades do estado, estes são lançados em terrenos baldios de zonas rurais, propiciando impactos ambientais de diferentes magnitudes, principalmente no que concerne a poluição do solo, da água e do ar, além da poluição estética e visual. 
O primeiro aterro sanitário do estado da Paraíba foi colocado em operação no ano de 2003 e veio substituir o denominado Lixão do Róger que na época era o local de disposição final dos resíduos sólidos urbanos coletados na cidade de João Pessoa e de demais outras cidades circunvizinhas. Localizado no Engenho Mussuré, no Distrito Industrial da cidade João Pessoa, foi projetado para receber e confinar diariamente algo em torno de 1.172 toneladas de resíduos sólidos urbanos em uma área de 100 hectares. O consórcio que administra o aterro sanitário é formado pelas administrações das cidades de JoãoPessoa, Bayeux, Cabedelo, Conde, Pitimbu e Santa Rita. O projeto do aterro prevê a construção de 29 células para receber resíduos sólidos domiciliares, de uma estação para tratamento de lixiviado, de unidades de triagem e de compostagem e a instalação de um incinerador para resíduos sólidos de serviços de saúde.

O segundo aterro sanitário do estado da Paraíba, está localizado na região metropolitana da cidade de Campina e foi projetado para confinar os resíduos sólidos urbanos produzidos e coletados na cidade de Campina Grande e as cidades de Boa Vista, Lagoa Seca e Puxinanã. Aterro foi projetado em uma área territorial de 80 hectares e encontra- se localizado no Distrito de Catolé de Boa Vista. É um aterro ainda muito novo, haja vista a sua operação ter sido iniciada no mês de agosto do ano de 2015, com previsão de 25 anos de vida útil. Recebe atualmente cerca de 500 toneladas diárias, quantitativo superior ao estimado no projeto original o que provavelmente comprometerá o tempo de vida útil de projeto do aterro, caso alguma outra alternativa no que concerne a redução da carga de confinamento de resíduos sólidos urbanos não seja adotada.

Além destes dois aterros sanitários, mais outras 13 cidades do estado da Paraíba já iniciaram o processo de construção de projeto de aterro sanitário o que vislumbra em possibilidade real de confinamento dos resíduos sólidos urbanos produzidos. Portanto, para um estado com 223 municípios, até a data atual apenas em torno de 11\% dos municípios são detentores de sistemas de confinamentos de resíduos sólidos urbanos.

No estado da Paraíba, do quantitativo de resíduos sólidos urbanos produzidos e coletados diariamente, em média 58\% (percentagem em peso) corresponde a matéria orgânica fermentável, 28\% de materiais potencialmente recicláveis e 14\% de rejeitos. Analisando estes percentuais e levando em consideração as diretrizes norteadoras da Lei 12.305/2010, pode ser constatado que no Brasil e no estado da Paraíba em particular a problemática sanitária e ambiental dos resíduos sólidos urbanos, está associada a falta de gestão.

Considerando que as etapas do processo de gerenciamento integrado de resíduos sólidos fossem implementas paulatinamente como ação integrada de política pública, seria propiciada favoravelmente as ações operacionais e financeiras do processo de coleta e tratamento dos resíduos sólidos urbanos.

Para uma população urbana de estimada em 3.433 .880 habitantes, no estado da Paraíba são produzidas aproximadamente por dia 1.600 toneladas de matéria orgânica putrescível, que poderia estar sendo biotransformada via aeróbia ou anaeróbia e gerando subprodutos de alto valor agregado, contribuindo para à redução de impactos sociais, econômicos e ambientais que estes materiais orgânicos putrescíveis vêm propiciando a população do estado da Paraíba, em especial as pessoas mais vulneráveis financeiramente.

Vale destacar também que a concepção no campo da Engenharia Sanitária de confinamento deste quantitativo de material orgânico putrescível em aterro sanitário, não é uma recomendável alternativa tecnológica, haja vista os impactos ambientais gerados, dentre os quais poderão ser destacados os elevados custos financeiros associados diretamente a aquisição de área, projeto de engenharia, operação e manutenção do aterro sanitário, além dos dois principais subprodutos gerados que são o biogás e o lixiviado. Portanto, é necessário e urgente no estado da Paraíba e no Brasil em geral, que o processo de confinamento de resíduos sólidos urbanos em aterro sanitário seja redimensionado, uma vez que, os aterros sanitários sejam projetados para o confinamento seguro da fração denominada rejeitos contidos nos resíduos sólidos urbanos.

Neste cenário proposto, considerando apenas os dois principais aterros sanitários do estado da Paraíba, que recebem atualmente cerca 1600 toneladas. dia $^{-1}$ de resíduos sólidos urbanos, passariam a receber algo em torno de 256 toneladas.dia ${ }^{-1}$ de 
material com características predominantemente inertes e que não geraria biogás e o lixiviado gerado passaria a ter reduzida a concentração de material orgânico de natureza não recalcitrante e de material nitrogenado.

É verdade que estas questões não serão resolvidas em curto período de tempo, porém é necessário que a construção de cenários alternativos no campo tecnológico seja iniciada e para isto já existe no campo legal a Lei 12.305/2010 que traçou diretrizes muito bem fundamentais neste aspecto. Doravante, resta aos municípios Paraibanos traças estratégias para que possam ser trabalhadas as seguintes diretrizes:

- Trabalhar o processo de redução da geração de resíduos sólidos urbanos como bandeira de ação de política pública.

- Implementar programas eficazes e consistentes de reciclagem e reutilização da fração de resíduos sólidos urbanos potencialmente recicláveis e/ou reutilizáveis, que no caso do estado da Paraíba é algo em torno de 32\% do total gerado, levando em consideração os aspectos sociais, econômicos e ambientais do município e entorno.

- Valorizar os trabalhadores e trabalhadoras dos serviços e limpeza pública municipal e todos aqueles que desenvolvem atividades associadas ao processo de reciclagem de formas orgânica ou não.

- Formatar programas de políticas públicas, procurando incentivar a participação popular no processo de limpeza pública da cidade de forma orgânica e continuada.

- Fazer cumprir os diplomas legais de âmbito municipal, estadual e federal no que concerne à coleta e tratamento de outros diferentes tipos de resíduos sólidos gerados em outros ramos de atividades no município.

- Em determinadas situações e em consonância com os diplomas legais, procurar contribuir no processo construção de parcerias consorciadas com demais municípios, objetivadas sempre para a preservação dos recursos naturais e a melhoria da qualidade de vida da população.

Se as gestões municipais passassem a considerar e implementar de forma gradativa e sincronizada estes princípios básicos, haveria em um espaço curto de tempo a otimização do processo de limpeza pública, com redução substancial de custos financeiros no próprio sistema e em demais outros, além da possibilidade real de tornar a cidade um lugar sustentável nos aspectos sociais, econômicos e ambientais.

Da área física total do estado da Paraíba, algo em torno de 35,4\% o que corresponde a uma área de 19.448 km2 poderá ser aplicada para exploração agrícola, em especial para as culturas de feijão caupi, milho, algodão herbáceo e cana de açúcar (Francisco et al., 2015).

O quantitativo estimado de resíduos sólidos urbanos coletados diariamente no estado da Paraíba é de 2.600 toneladas.dia ${ }^{-1}$, o que corresponde a um quantitativo produzido de matéria orgânica putrescível de aproximadamente 1.430,3 toneladas.dia-1. Portanto, considerando apenas esta matriz de produção de matéria orgânica putrescível e que esta matéria orgânica seja utilizada para produção de composto orgânico, seria produzida um total de 858 toneladas de composto orgânico. $\mathrm{dia}^{-1}$, o que propiciaria uma aplicação de 15,9 toneladas de composto orgânico . (ha.ano) ${ }^{-1}$, na área potencialmente agricultável do estado da Paraíba.

Aplicando-se este composto orgânico nos solos agrícolas do estado da Paraíba, em termos de macronutrientes seria incorporada as seguintes magnitudes: 776,0 kgNTK. ano ${ }^{-1}$;. 551,0 kgCa. ano ${ }^{-1}$ e de $3.878 \mathrm{kgNPK}^{-}$ano ${ }^{-1}$ Em termos financeiros, estima-se que seria gerado um quantitativo de recursos da ordem de $\mathrm{R} \$ 18.615 .000,00$. ano $^{-1}$.

Quando levado em consideração o retorno para o ciclo produtivo das demais outras frações constituintes dos resíduos sólidos urbanos, tais como papel, papelão, plásticos, material ferroso e não ferroso e vidro, o retorno financeiro seria ainda mais expressivo, com redução significativa dos impactos ambientais. 
Portanto, dentro de um contexto sustentável, do ponto de vista social, econômico e ambiental, será necessário propiciar de forma contínua e sincronizada a redução da taxa de geração per capita de resíduos sólidos urbanos e consequentemente o aproveitamento integral do quantitativo das diversas frações geradas nas cadeias produtivas (Silva, 2008). Isto só será alcançado quando do cumprimento do arcabouço legal da política nacional de resíduos sólidos e da participação ativa de toda a sociedade.

Uma outra alternativa, seria a utilização do potencial energético desta matéria orgânica de maneira sustentável no campo ambiental e social. É lógico que será necessário a definição de algumas prioridades neste contexto, porém é uma alternativa que não poderá ser desprezada. A matéria orgânica existe e quando não for aproveitada de forma racional via processo aeróbio ou anaeróbio, deverá ser lançada em aterros sanitários, ou até mesmo em lixões a céu aberto e os impactos ambientais advindos serão de significativas magnitudes. Em consonância com os ditames legais em especial ancorados na Lei 12.305/2010, a orientação técnica é trabalhar no sentido da redução da geração de resíduos sólidos e do quantitativo gerado propiciar condições para sua inclusão de forma segura e sustentável no ciclo produtivo (Leite et al., 2009).

É necessário atualmente encarar a reciclagem das diversas frações recicláveis dos resíduos sólidos como uma ação governamental e não como meio de sobrevivência de parte da população brasileira que já foi marginalizada oficialmente do mercado formal de trabalho. Não é possível em um país de dimensão continental que gera diariamente algo em torno de 210.000 toneladas RSU.dia ${ }^{-1}$, com percentual de matéria orgânica superior a 50\% (percentagem em peso) e com mais 35\% de outros tipos de resíduos com potencial de serem totalmente recicláveis, ainda não priorizar a reciclagem de maneira prioritária dentro da matriz de tratamento de resíduos sólidos (Lino et al., 2013). Será necessário que as prefeituras dos municípios brasileiras e paraibanos passem a ter consciência da gravidade do lançamento inadequado dos resíduos sólidos urbanos, haja vista as vulnerabilidades sociais, econômicas e ambientais da região. Portanto, quando levado em consideração o somatório de uma série de fatores, desde a redução de geração de resíduos sólidos urbanos, o aproveitamento racional e sustentável de suas frações recicláveis e a destinação correta dos rejeitos, passaremos a ter no campo do saneamento básico e da sustentabilidade ambiental significativos avanços.

\section{Conclusão}

No estado da Paraíba são produzidos diariamente algo em torno de 2.737 toneladas de resíduos sólidos urbanos. Deste total, 56\% em média corresponde a matéria orgânica putrescível o equivalente a 1.532,9 toneladas por dia, que poderá ser aproveitada integralmente em processo aeróbio ou anaeróbio, evitando a pulverização de macro e micro vetores e o lançamento de efluentes líquidos e gasosos no meio ambiente. Algo em torno de 32,5\% corresponde a outras frações potencialmente recicláveis, totalizando um percentual de 88,5\% passível de aproveitamento, restando apenas 11,5\% de rejeito, que é a fração que deveria ser confinada em aterro sanitário.

No geral, o quantitativo dos 56\% de matéria orgânica putrescível presente nos resíduos sólidos urbanos, poderá ser aproveitado na produção de composto orgânico, que no caso do estado da Paraíba poderia atender a uma demanda real, ou ser aproveitada na produção de energia, em especial para ser aplicada de forma pontual em zona rural, em atendimento de demandas agrícolas e pecuárias. Portanto, pode-se assegurar, que não é seguro em nenhum aspecto o confinamento de resíduos sólidos urbanos em aterro sanitário, haja vista a complexidade do processo de confinamento em si, a demanda de área requerida e custos financeiros associados, além dos subprodutos gerados e dos impactos ambientais do entorno.

A contribuição para estudos posteriores parte da abrangência da pesquisa a outros estados do Brasil, de forma a gerar uma análise ampla sobre a coleta e destinação de resíduos sólidos urbanos. Se faz também necessário avaliar os parâmetros sociais e ambientais, de forma que sejam feitas novas correlações a fim de distinguir as principais contribuições para a geração 
Research, Society and Development, v. 10, n. 1, e33110111781, 2021 (CC BY 4.0) | ISSN 2525-3409 | DOI: http://dx.doi.org/10.33448/rsd-v10i1.11781

e disposição final de RSU, com o objetivo de minimizar a geração dos mesmos. Destaca-se que este é um grande problema da sociedade e que somente com o envolvimento e compromisso de todos, é possível conseguir encontrar caminhos sustentáveis.

\section{Referências}

ABRELPE. (2017). Roteiro para encerramento de lixões. Associação Brasileira de Empresas de Limpeza Pública e Resíduos Especiais - ABRELPE. http://abrelpe.org.br/roteiro-para-encerramento-de-lixoes/

Figueiredo, F. F. (2011). Panorama dos resíduos sólidos brasileiros: análises de suas estatísticas. Biblio 3W. Revista Bibliográfica de Geografía y Ciencias Sociales, 17 (928), 10.

Francisco, P. R. M., Pereira, F. C., Brandão, Z. N., Zanta, J. H., Santos, D., \& Silva, J. V. N. (2015). Mapeamento da aptidão Edáfica para Fruticultura Segundo o Zoneamento Agropecuário do estado da Paraíba. Revista Brasileira de Geografia Física. 8 (2).

Instituto Brasileiro De Geografia e Estatística. (2013) Indicadores de desenvolvimento sustentável: Brasil 2010. Rio de Janeiro: Ministério do Planejamento, Orçamento e Gestão. https://biblioteca.ibge.gov.br/visualizacao/livros/liv59908.pdf.

Jacobi, P., \& Besen, G. R. (2011). Gestão de resíduos sólidos em São Paulo: desafios da sustentabilidade. Estudos Avançados. 25(71):135-158.

Lei no 12.305, de 2 de Agosto de 2010. Política Nacional de Resíduos Sólidos. Brasil, 2010. http://www.agricultura.gov.br/assuntos/vigilanciaagropecuaria/ivegetal/bebidas-arquivos/lei-no-12-305-de-02-de-agosto-de2010 pdf/view.

Leite, V. D., Lopes, W. S., Sousa, J. T., Prasad, S., \& Silva, S. A. (2009). Tratamento Anaeróbio de Resíduos Sólidos Orgânicos com Alta e Baixa Concentração de Sólidos. Revista Brasileira de Engenharia Agrícola e Ambiental. 13(2), 34-47.

Leite, V. D., Silva, S. A., Lopes, W. S., \& Sousa, J. T. Resíduos sólidos urbanos no estado da Paraíba: aspectos conjunturais. I Simpósio Nordestino de Saneamento Ambiental. Paraíba, 2010.

Leite, V. D., Sousa, J. T., Lopes, W. S., \& Luna, M. L. D. (2009). Resíduos Sólidos Urbanos no Estado da Paraíba: Fossilização do Caos. Revista ECOS. 1, 21 45 .

Lino, F. A. M., \& Ismail, K. A. R. (2013) Contribution of recycling of municipal solid waste to the social inclusion in Brazil, Journal of Waste Manage. 1-4.

Ministério das Cidades. Secretaria Nacional de Saneamento Ambiental / Plano Nacional de Saneamento Básico - PLANSAB. Brasília, dezembro de 2013. https://www.cidades.gov.br/images/stories/ArquivosSNSA/PlanSaB/plansab_texto_edit ado_para_download.pdf.

Ministério do Meio Ambiente (MMA). Plano Nacional de Resíduos Sólidos. Brasília, agosto/ 2012, 103 p. https://www.mma.gov.br/cidadessustentaveis/residuos-solidos/politica-nacional-de-residuos-solidos.

Pereira A. S. et al. (2018). Metodologia da pesquisa científica. Ed. https://repositorio.ufsm.br/bitstream/handle/1/15824/Lic_Computacao_Metodologia-Pesquisa-Cientifica.pdf?sequence=1 .

Pesquisa Nacional por Amostra de Domicílio, Rio de Janeiro, 2014. https:/www.ibge.gov.br/estatisticas/sociais/trabalho/9127-pesquisa-nacional-poramostra-de-domicilios.html?=\&t=downloads.

Santos, A. B. (2019). Caracterização, Tratamento e Gerenciamento de Subprodutos de Correntes de Esgoto Segregadas e não Segregadas em Empreendimentos Habitacionais; in: Oportunidades e Desafios na Implementação de Estações de Tratamentos de Esgotos. 23 - 47.

Silva, A. G., Leite, V. D., Silva, M. M. P., Prasad, S., \& Feitosa, W. B. S. (2008). Compostagem aeróbia conjugada de lodo de tanque séptico e resíduos sólidos vegetais. Revista de Engenharia Sanitária e Ambiental, 13 (4), 71-379. 